\title{
Água e relações internacionais
}

\section{ÉVERTON VIEIRA VARGAS}

Até há poucos anos, as inter-relações entre meio ambiente, desenvolvimento econômico e social, mudanças globais e suas repercussões na interação entre os Estados ocupavam apenas a atenção de especialistas e pareciam uma questão distante dos interesses do cidadão comum. Progressivamente, esse quadro foi se alterando. A preocupação com a conservação dos recursos hídricos pode ser vista como precursora da consciência ambiental enquanto manifestação social coletiva. Mesmo no passado, quando a interdependência entre as diversas dimensões do meio ambiente era menor do que é hoje, os rios tiveram um papel pioneiro no despertar para a urgência e a amplitude das questões ambientais e seu potencial efeito nas relações entre os Estados ${ }^{1}$.

A conscientização sobre possíveis danos transfronteiriços da poluição desencadeou um movimento orientado à diminuição dos índices de contaminação, bem como promoveu uma valorização dos recursos hídricos considerados não somente essenciais para a manutenção da vida, mas também como recurso econômico importante. Daí a repercussão da escala e da intensidade dos problemas com que se têm defrontado as nações na manutenção de seu patrimônio hídrico, fazendo com que a água ganhe progressiva saliência como item da agenda internacional ${ }^{2}$.

A partir dos anos 70, a água passou a constar como um dos capítulos mais importantes da agenda internacional. Após a Conferência das Nações Unidas sobre Meio Ambiente Humano, realizada em Estocolmo, em 1972, a Conferência de Mar del Plata, em 1977, foi o primeiro evento multilateral genuinamente global a debruçar-se, sob os auspícios das Nações Unidas, sobre a problemática da água. O Plano de Ação então adotado reconheceu a conexão intrínseca entre os projetos de desenvolvimento de recursos hídricos e suas significativas repercussões físicas, químicas, biológicas, sanitárias e sócio-econômicas. Declarou, ademais, a Década de 1980 como a "Década Internacional do Fornecimento da Água Potável e do Saneamento" sob a premissa de que "todos os povos, quaisquer que sejam seu estágio de desenvolvimento e suas condições sociais e econômicas, têm direito ao acesso à água potável em quantidade e qualidade à altura de suas necessidades básicas". ${ }^{3}$

A Conferência das Nações Unidas sobre Meio Ambiente e Desenvolvimento, celebrada no Rio de Janeiro, em 1992, reafirmou e consagrou conceitos de crucial interesse para os países em desenvolvimento, a saber: o desenvolvimento sustentável; o princípio das responsabilidades comuns, porém diferenciadas, entre os países, no que diz respeito à proteção do meio ambiente; a soberania dos Estados 
sobre os recursos naturais existentes em seus territórios e a responsabilidade de que sua exploração não acarrete danos fora de sua jurisdição; e o princípio da precaução. Esses conceitos incorporados nos documentos adotados pela Conferência, encerram múltiplos sentidos e constituem pilares para a ação da comunidade internacional. A Declaração do Rio sobre Meio Ambiente e Desenvolvimento e a Agenda 21 são respectivamente um conjunto de preceitos para a conduta dos Estados e um plano de ação global para a cooperação na área ambiental. Tanto a Declaração do Rio quanto a Agenda 21 foram arduamente negociadas pelos Governos durante o processo preparatório da Conferência - que incluiu contribuições da sociedade civil - e foram aprovadas por unanimidade pelos mais de cem Chefes de Estado e de Governo presentes à Rio-92. Daí a importância de sua preservação do espírito e do conteúdo dos compromissos frente a tentativas de qualificá-los, diluí-los ou minimizar sua natureza e sua abrangência.

Os recursos hídricos são um capítulo relevante da Agenda 21, não só por ser o mais extenso de todos, mas também por tocar um ponto de interesse estratégico, especialmente para o Brasil. Foi reconhecido "o caráter multissetorial do desenvolvimento dos recursos hídricos no contexto do desenvolvimento socioeconômico, bem como os interesses múltiplos na utilização desses recursos para o abastecimento de água potável e saneamento, agricultura, indústria, desenvolvimento urbano, geração de energia hidroelétrica, pesqueiros de águas interiores, transporte, recreação, manejo de terras baixas e planícies e outras

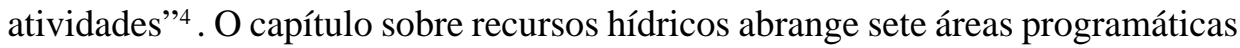
que cobrem os aspectos de desenvolvimento e manejo integrado; avaliação; proteção dos recursos hídricos, da qualidade da água e dos ecossistemas aquáticos; abastecimento de água potável e saneamento; água e desenvolvimento urbano sustentável; água para produção sustentável de alimentos e desenvolvimento rural sustentável; e impactos da mudança do clima sobre os recursos hídricos ${ }^{5}$.

O cumprimento pelos países em desenvolvimento dos objetivos e metas estabelecidos na Agenda 21 está condicionado à sua capacidade e aos recursos disponíveis por meio de cooperação bilateral ou multilateral na forma de substanciais recursos financeiros novos e adicionais. Igualmente, a implementação da Agenda está vinculada à colocação em prática pela comunidade internacional, em particular pelos países industrializados, de medidas que promovam a cooperação tecnológica e que permitam a transferência, em condições favoráveis para os países em desenvolvimento, do conhecimento técnico, científico e tecnológico conjugado com o aumento da capacidade desses países de usá-lo de modo eficiente e de promover o desenvolvimento a partir da tecnologia transferida ${ }^{6}$.

O crescimento dos índices de poluição e de contaminação das águas devido à ação humana, num sentido que limitem a capacidade de atuação dos Estados na utilização do capital natural sobre o qual têm jurisdição, poderia aprofundar as desigualdades físicas e econômicas entre as nações, bem como suscitar o 
aparecimento de novas formas de hegemonia. Saliente-se que os recursos hídricos por se situarem na esfera de soberania dos Estados não comportam uma discussão que tente reduzi-los à condição de bem global, isto é, dar-lhes o status de coisa comum de todos. Por outro lado, a evolução do conhecimento sobre as múltiplas dimensões dos recursos hídricos e as especificidades de seu manejo também têm revelado a importância da cooperação financeira e tecnológica internacional para a promoção das melhores práticas para a gestão daqueles recursos.

Recorde-se que a maior parte da água doce ainda disponível no mundo encontra-se na América do Sul, cujos países têm o direito de explorá-la de forma sustentável, em beneficio do bem-estar de seus povos. Na consideração da importância dos recursos hídricos para o Brasil, cumpre ter presente as características intrínsecas da sociedade brasileira: entre outros elementos registrese uma elevada urbanização, um sofisticado parque industrial, uma agricultura que coloca o país entre os grandes produtores de alimentos do mundo; ao mesmo tempo apresenta-se a existência de grandes desigualdades sociais, uma significativa área do território em condições semi-áridas (o polígono das secas) e uma região, com quase $50 \%$ da superfície do País, que detém 70\% dos recursos hídricos (a Amazônia). A complexidade da sociedade brasileira e a diversidade das condições naturais vigentes em nosso território requerem que nossa ação diplomática, no que se refere aos recursos hídricos, analise em profundidade as repercussões de eventuais compromissos internacionais para a soberania do país ou para a acomodação dos diferentes interesses que se manifestam no plano interno.

A questão dos recursos hídricos compartilhados ocupa há séculos a atenção daqueles envolvidos com a condução dos negócios de Estado e dos que labutam diretamente na produção de bens e serviços. Trata-se de um dos temas mais antigos da diplomacia, pois, se refere não só ao uso dos recursos hídricos, mas também ao exercício da soberania dos Estados. A Agenda 21 também reconheceu que "os recursos hídricos transfronteiriços são de grande importância para os Estados ribeirinhos. Nesse sentido, a cooperação entre esses Estados pode ser desejável em conformidade com os acordos existentes e/ou arranjos pertinentes, levando em consideração os interesses de todos os Estados ribeirinhos envolvidos" ". Em algumas regiões do planeta, a escassez natural de água é ainda hoje uma questão importante nos processos de redução das tensões e da promoção da boa vizinhança.

Para o Brasil, trata-se de matéria cuja importância extrapola o aspecto técnico da utilização das águas para fins de geração de energia, irrigação agrícola ou conservação do meio ambiente. $\mathrm{O}$ fato de as linhas de fronteira serem em grande extensão definidas pelos cursos de diversos rios inscreve necessariamente o tema dos recursos hídricos no âmbito da política externa. No Brasil, o compartilhamento de um imenso potencial hídrico tanto na fronteira norte quanto na sul serviu de base para o estabelecimento de uma teia de instrumentos jurídicos ${ }^{8}$ para estimular a cooperação com vistas ao ótimo aproveitamento dos grandes 
recursos naturais existentes e assegurar, mediante o uso racional, sua preservação para as gerações futuras. A utilização de recursos hídricos compartilhados ou sucessivos constitui uma dimensão importante do relacionamento do Brasil com os países vizinhos cobertos pelo complexo fluvial da Bacia do Prata.

São justamente o potencial econômico desses recursos, os possíveis impactos de sua utilização e a condição de país ribeirinho superior que, historicamente, levaram o Brasil a procurar harmonizar seus interesses de utilização dos recursos da Bacia do Prata com aqueles dos países depositários, a jusante, de águas compartilhadas. Com esse intuito, foram alcançados entendimentos em nível bilateral e regional, nos quais a atuação diplomática brasileira sempre se pautou pela necessidade de salvaguardar a autonomia do país na implementação e na operação de projetos hidrelétricos, hídricos e de navegação, sem ignorar, entretanto, os interesses específicos de países vizinhos.

A questão da utilização de recursos hídricos compartilhados foi o centro das tensões que perpassaram o relacionamento Brasil-Argentina durante toda a década de 1970. O diferendo acerca da construção de Itaipu, solucionado apenas em 1979, com a assinatura do Acordo Tripartite Brasil-Paraguai-Argentina, é caso paradigmático da sensibilidade política dos recursos hídricos para as relações entre países vizinhos, bem como da relevância da negociação diplomática para assegurar o desenvolvimento nacional.

Pode-se afirmar que os acordos celebrados pelo Brasil com os países fronteiriços consagram em seus propósitos a vontade política das partes contratantes de elevar o nível sócio-econômico das respectivas populações, em especial daquelas que habitam a faixa de fronteira; de conservar o meio ambiente; de promover o desenvolvimento industrial; de unir esforços para o aproveitamento da água para o controle de inundações, a promoção da irrigação, o estímulo à agricultura, o incremento à navegação e da geração de energia. Esses acordos denotam a continuidade e a consistência da política exterior brasileira com os princípios que nortearam a ação do Barão do Rio Branco na negociação dos tratados de limites que fixaram as fronteiras brasileiras no início do século XX. Numa perspectiva mais contemporânea, os acordos revelam uma precoce e sofisticada compreensão acerca das inter-relações entre meio ambiente e desenvolvimento e sua importância para a aproximação econômica e para a convergência política entre os parceiros ${ }^{9}$.

O cruzamento das dimensões local e global da questão ambiental faz com que sua regulação jurídica tenha como pressuposto as repercussões daquelas dimensões para a ordem internacional. Por outro lado, se no plano interno a participação da sociedade civil é estratégica para qualquer empreendimento de proteção do meio ambiente, em nível internacional não há como deixar de reconhecer o papel preponderante que cabe aos Estados. Acrescente-se que, na estruturação de um regime jurídico interno ou internacional, apenas o Estado, única instituição legitimamente apta a obrigar o cumprimento das determinações legais, tem 
possibilidade de estabelecer padrões de proteção ambiental juridicamente exigíveis. Daí a importância do fortalecimento das instituições nacionais que tratam dos recursos hídricos, as quais ao implementarem as políticas públicas no plano interno oferecem importante respaldo para a atuação do Itamaraty no cenário externo.

A multiplicidade de aspectos envolvidos na questão dos recursos hídricos mostra que seu tratamento internacional coloca em jogo interesses vitais para o Brasil. Há, portanto, que estar atento para as dimensões de conteúdo e de forma presentes na ação diplomática. Isso implica compreender os múltiplos interesses em jogo nas discussões internacionais sobre a água: a cooperação internacional contemporânea obedece a uma lógica utilitarista e tem resultado num equilíbrio imperfeito dos antagonismos entre as pretensões individuais e as acomodações coletivas.

Maio de 2000

\section{Notas}

1 Exemplos disso são os acordos sobre rios fronteiriços e navegação, valendo citar a propósito o acordo sobre a navegação no Rio Reno e o Tratado de 1909 entre os Estados Unidos e o Reino Unido sobre Águas Fronteiriças entre os Estados Unidos e o Canadá. Por este último ajuste, ambos se comprometiam a não poluir cada lado da fronteira de modo que pudesse resultar em prejuízo à saúde ou à propriedade do outro.

2 O tema foi, por exemplo, objeto do Fórum Mundial da Água e da Conferência Ministerial sobre a Água celebrados na Haia em março passado.

3 Relatório da Conferência das Nações Unidas sobre a Água. (Mar del Plata, 14-25 de março de 1977). Cap. I. Resolução II.

4 Conferência das Nações Unidas sobre Meio Ambiente e Desenvolvimento. (Rio de Janeiro, 1992). Agenda 21. Capítulo 18. Parágrafo 18.3. Brasília: Câmara dos Deputados, Coordenação de Publicações, 1995. p. 297.

$5 \quad$ Id. ib. Parágrafo 18.5. p. 268.

$6 \quad$ Id.ib. Capítulos 33 e 34.

$7 \quad$ Id. ib. Parágrafo 18.4. p. 268.

8 Exemplos desses instrumentos jurídicos são o Tratado da Bacia do Prata, de 1969, concluído com a Argentina, Bolívia, Paraguai e Uruguai; o Tratado para o Aproveitamento dos Recursos Hídricos do Rio Paraná, firmado entre o Brasil e o Paraguai, em 1973; o Tratado da Bacia da Lagoa Mirim, de 1977, celebrado com o Uruguai; o Tratado de Cooperação Amazônica, de 1978, assinado com a Colômbia, Equador, Guiana, Peru, Suriname e Venezuela; e o Acordo de Cooperação para o Aproveitamento dos Recursos Naturais e o Desenvolvimento da Bacia do Rio Quaraí, concluído com o Uruguai, em 1992.

9 Note-se que esses efeitos extrapolam as relações entre os Estados para repercutirem também nas parcerias entre os setores produtivos dos países envolvidos e na percepção dos cidadãos sobre as sociedades vizinhas. 